Title: Intravenous and Intramuscular Allopregnanolone for Early Treatment of Status Epilepticus: Pharmacokinetics, Pharmacodynamics, and Safety in Dogs

Authors: Irene Vuu, ${ }^{1}$ Edward E Patterson, ${ }^{2}$ Chun-Yi Wu, ${ }^{3}$ Dorota Zolkowska, ${ }^{3}$ llo E Leppik, ${ }^{4}$ Michael A Rogawski, ${ }^{3}$ Gregory A Worrell, ${ }^{5}$ Vaclav Kremen, ${ }^{5}$ James C Cloyd, ${ }^{4}$ Lisa D Coles ${ }^{4}$

Primary Laboratory of Origin: James C. Cloyd Laboratory, Center for Orphan Drug Research, University of Minnesota College of Pharmacy, Minneapolis, MN 
Running Title: Allopregnanolone PK-PD for Treatment of Status Epilepticus

Authors: Irene Vuu, Edward E Patterson, Chun-Yi Wu, Dorota Zolkowska, llo E Leppik, Michael A Rogawski, Gregory A Worrell, Vaclav Kremen, James C Cloyd, Lisa D Coles

Corresponding Author: Lisa D Coles,

University of Minnesota College of Pharmacy, Experimental \& Clinical Pharmacology

4-214 McGuire Translational Research

2001 6th St SE

Minneapolis, MN 55455

(612) 624-1861

durh0016@umn.edu

Number of text pages: 24

Number of tables: 5

Number of figures: 7

Number of words in Abstract: 250

Number of words in Introduction: 740

Number of words in Discussion: 899

\section{List of Nonstandard Abbreviations}

\begin{tabular}{|l|l|}
\hline ACN & acetonitrile \\
\hline ALLO & allopregnanolone \\
\hline ANOVA & analysis of variance \\
\hline AUC & area under the concentration-time curve \\
\hline BZD & benzodiazepine \\
\hline C $_{\max }$ & maximum concentration \\
\hline CL & clearance \\
\hline DFP & diisopropyl fluorophosphate \\
\hline F & bioavailability \\
\hline iEEG & intracranial electroencephalograph \\
\hline mGCS & modified Glasgow coma scale \\
\hline NCA & noncompartmental analysis \\
\hline
\end{tabular}




\begin{tabular}{|l|l|}
\hline OFV & objective function value \\
\hline PD & pharmacodynamic \\
\hline PK & pharmacokinetics \\
\hline PKPD & pharmacokinetic-pharmacodynamic \\
\hline PB & phenobarbital \\
\hline SE & status epilepticus \\
\hline$t_{1 / 2}$ & half-life \\
\hline$t_{\max }$ & time to maximum concentration \\
\hline TETS & tetramethylenedisulfotetramine \\
\hline UPLC-MS & ultra high-performance liquid chromatography-mass spectrometry \\
\hline V & volume of distribution \\
\hline
\end{tabular}

Recommended section assignment: Neuropharmacology 


\section{Abstract}

Allopregnanolone (ALLO) is a neurosteroid that modulates synaptic and extrasynaptic $\mathrm{GABA}_{\mathrm{A}}$ receptors. We hypothesize that ALLO may be useful as first-line treatment for status epilepticus (SE). Our objectives were to 1) characterize ALLO pharmacokineticspharmacodynamics following intravenous (IV) and intramuscular (IM) administration and 2) compare IV and IM ALLO safety and tolerability. Three healthy dogs and two with a history of epilepsy were used. Single ALLO IV doses ranging from 1-6 mg/kg were infused over 5 min or injected IM. Blood samples, vital signs, and sedation assessment were collected up to 8 hours post-dose. Intracranial EEG (iEEG) was continuously recorded in one dog. IV ALLO exhibited dose-proportional increases in exposure, which were associated with an increase in absolute power spectral density in all iEEG frequency bands. This relationship was best described by an indirect link PK-PD model where concentration-response was described by a sigmoidal Emax equation. Adverse events included site injection pain with higher IM volumes and ataxia and sedation associated with higher doses. IM administration exhibited incomplete absorption and volume-dependent bioavailability. Robust iEEG changes following IM administration were not observed. Based on PK/PD simulations, a $2 \mathrm{mg} / \mathrm{kg}$ dose infused over 5 minutes is predicted to achieve plasma concentrations above the $\mathrm{EC}_{50}$, but below those associated with heavy sedation. This study demonstrates that ALLO is safe and well tolerated when administered at $1-4 \mathrm{mg} / \mathrm{kg}$ IV and up to $2 \mathrm{mg} / \mathrm{kg} \mathrm{IM}$. The rapid onset of effect following IV infusion suggests that ALLO may be useful in the early treatment of SE. 


\section{Significance Statement}

The characterization of the pharmacokinetics and pharmacodynamics of

allopregnanolone is essential in order to design clinical studies evaluating its

effectiveness as an early treatment for status epilepticus in dogs and people. We have

proposed a target dose/therapeutic range for a clinical trial in canine status epilepticus. 


\section{Introduction}

Human status epilepticus (HSE) is a life-threatening neurological emergency defined as a prolonged seizure or recurrent seizures without complete recovery of consciousness (Trinka et al. 2015). It is the result of either a failure of the mechanisms responsible for seizure termination, or an initiation of mechanisms that lead to abnormally prolonged seizures (Trinka et al. 2015). A reported 152,000 cases with 42,000 deaths (28\%) occur each year in the United States (DeLorenzo et al. 1995). Companion canines have naturally occurring epilepsy at a comparable prevalence to that in people (1-6\%) and are the only other species with epilepsy at this rate (Potschka et al. 2013). Prolonged or recurrent seizures also occur in dogs, a condition known as canine SE (CSE). In dogs with epilepsy, the prevalence of SE has been reported as high as 59\%, and is associated with a decreased mean life span compared to dogs with epilepsy without CSE (Saito et al. 2001; Bateman and Parent 1999). Nineteen to $25 \%$ of dogs brought to a veterinary referral center for treatment of CSE or recurrent seizures or have had an episode of CSE died or were euthanized for reasons directly related to their seizure disorder (Saito et al. 2001; Bateman and Parent 1999).

Current guidelines for initial SE treatment in humans and dogs call for administration of an adequate dose of a benzodiazepine (BZD) (Alldredge et al. 2001; Glauser et al. 2016; Blades Golubovic and Rossmeisl 2017). Nevertheless, one-third to one-half of human patients do not respond (Silbergleit et al. 2012; Treiman et al. 1998). BZD-refractory SE is known as established SE (ESE) (Falco-Walter and Bleck 2016). Failure of BZDs in SE may be due to several factors, including inadequate dosing, delayed initiation of treatment, or seizure etiology. Prolonged seizure duration initiates 
cellular changes in the affected neurons, including endocytosis of synaptic BZDsensitive $\mathrm{GABA}_{\mathrm{A}}$ receptors (containing $\beta 2 / 3$ and/or $\gamma 2$ subunits); increased expression of BZD-insensitive $\mathrm{GABA}_{\mathrm{A}}$ receptors (containing a4 subunits, commonly in extrasynaptic regions) at synapses; and increased recruitment of AMPA receptors to synapses (Chen and Wasterlain 2006; Naylor, Liu, and Wasterlain 2005; Kapur 2000). These changes, taken together, promote continuation of seizures. The failure of the first treatment carries with it the increased risk of morbidity and mortality including cardio-respiratory compromise and neuronal injury. Hence, it is critical to treat SE immediately and with the most effective available agent.

Allopregnanolone (ALLO) is a neurosteroid that was FDA-approved for the treatment for severe post-partum depression (ZULRESSO ${ }^{\mathrm{TM}}$ [package insert]). It has been shown to be highly effective in terminating SE in rodent models, including pilocarpine and perforant path stimulation rodent models (Kokate et al. 1996; Frye 1995). Moreover, ALLO terminates BZD-refractory SE in diverse models, including the kainate model (Rogawski et al. 2013) and a model of SE induced by the nerve agent tetramethylenedisulfatetramine (Zolkowska, Wu, and Rogawski 2018). In these studies, ALLO administered 40 minutes after seizure onset, a time when the seizures are insensitive to BZD, effectively terminated behavioral and electrographic seizures. The basis through which ALLO is able to terminate BZD-refractory SE is not completely understood, but has been hypothesized to relate to the ability of ALLO to act as a positive allosteric modulator of both synaptic and extra-synaptic $\mathrm{GABA}_{\mathrm{A}}$ receptors (Rogawski et al. 2013). BZD act exclusively on synaptic $\mathrm{GABA}_{\mathrm{A}}$ receptors, which as noted above are internalized as SE progresses and become progressively unavailable 
(Rogawski et al. 2013). It is noteworthy that ALLO also acts on BZD-insensitive GABA receptors that increase in abundance at synapses as SE continues (Kapur 2000). The actions of ALLO on both synaptic BZD-insensitive and extrasynaptic $\mathrm{GABA}_{\mathrm{A}}$ receptors provide a novel mechanism of action to that of BZDs (Carver and Reddy 2013; Belelli et al. 2002).

In light of the suboptimal response rate of BZDs, we hypothesize that ALLO possesses the requisite pharmacologic, physicochemical, and pharmacokinetic (PK) properties to serve as an early treatment for SE. One approach to testing this hypothesis is the use of dogs with naturally-occurring epilepsy, which is similar to human epilepsy in electroencephalographic presentation and response to therapy (Berendt et al. 1999; Patterson et al. 2015). Our approach is to characterize the relationship between exposure and response in dogs as a step towards designing clinical trials in both dogs and humans. In this study, we characterized the pharmacokinetics, pharmacodynamics, and safety/tolerability of intravenous (IV) and intramuscular (IM) ALLO in dogs to provide dosing data for a clinical study of CSE; which, in turn, would provide a proof of concept to conduct studies in human SE.

\section{Materials and Methods}

Study Animals and Safety Monitoring Five dogs with $(n=2)$ and without $(n=3)$ a history of seizures were used (Supplemental Table 1). One of the dogs with a history of seizures had recurrent seizures despite being on phenobarbital (PB) maintenance regimen. Approval was obtained through the Institutional Animal Care and Use Committee of the University of Minnesota prior to the initiation of the study. The dogs 
were housed at the University of Minnesota College of Veterinary Medicine. The dog on PB was previously implanted with a device which wirelessly transmits continuous iEEG recordings (Kremen et al. 2018). On study days, each dog participating in the study was removed from their kennel to have a central-line sampling catheter implanted an hour prior to study start. On days where IV ALLO was administered, a peripheral-line catheter was also implanted for the ALLO administration to be in separate line and limb from the sampling line. Drug administration took place in a procedure room away from the dog's kennel. The dogs were fasted prior to and fed no sooner than 2 hours after drug administration.

Study Drug At the time the study was conducted, there was no commercial formulation of allopregnanolone. Therefore, allopregnanolone was custom synthesized with a purity of $99.9 \%$, using a high-performance liquid chromatography assay. A concentrated solution consisting of $6 \%$ allopregnanolone and $24 \%$ sulfobutyl ether $\beta$-cyclodextrin (Dexolve ${ }^{\mathrm{TM}}$ ) dissolved in a $0.9 \%$ sodium chloride solution (normal saline) was prepared and target concentrations were confirmed by the Rogawski laboratory at the University of California, Davis as previously reported (Zolkowska, Wu, and Rogawski 2018). As an additional step for quality control, following the completion of each experiment, a sample of the diluted allopregnanolone solution (see below) was sent to the Rogawski laboratory for confirmation of concentration. The concentrate was shipped frozen to the University of Minnesota. The frozen ALLO was thawed overnight prior to study date and diluted with normal saline (1 part ALLO : 0 to 3 parts normal saline) prior to IV and IM administration for a final allopregnanolone concentration of $1.5-6 \mathrm{mg} / \mathrm{mL}$. IM studies 
were also conducted with concentrates consisting of $11 \%$ and $14 \%$ allopregnanolone and $40 \%$ Dexolve ${ }^{\mathrm{TM}}$ dissolved in normal saline and was not diluted prior to administration.

Starting Dose Rationale Basal levels of ALLO in healthy, pregnant women have been reported to reach as high as $50 \mathrm{ng} / \mathrm{mL}$ (Luisi et al. 2000). Further, IM doses of 3-6 $\mathrm{mg} / \mathrm{kg}$ were effective in terminating status epilepticus in mice and rats (Zolkowska, Wu, and Rogawski 2018; Dhir et al. 2020). Using preclinical and clinical data reported in the literature (Irwin et al. 2015; Timby et al. 2006) and simple allometry, scaling coefficients for clearance and volume were calculated by taking the natural log of weight of three different species (mouse, rabbit, and human) and plotting it against the natural log of the pharmacokinetic parameter to calculate a slope from the trendline. We predicted a fiveminute infusion of $1 \mathrm{mg} / \mathrm{kg}$ was estimated to maintain plasma concentrations in the 50 $\mathrm{ng} / \mathrm{mL}$ range for 30 minutes. Hence, we used a $1 \mathrm{mg} / \mathrm{kg}$ dose to initiate our studies.

Study Design Three healthy dogs and one dog with a history of seizures were given single IV doses of ALLO ranging from $1-4 \mathrm{mg} / \mathrm{kg}$ by a 5 -minute infusion via a catheterized peripheral vein (Table 1). One to two dogs were studied at each dose level. Whole blood samples ( 2 to $5 \mathrm{~mL}$ ) were collected via a catheterized central vein at predose and at 3-, 5-, 15-, 30-, 45-minutes, 1-, 2-, 4-, and 6-hours post-infusion. A washout period of at least 1 week was used.

After the completion of the IV dose escalation study, PK studies were undertaken following IM administration in two healthy dogs and two dogs with a history 
of seizures (one on chronic PB) in a dose-escalation manner. However, in addition to varying the doses, we also administered different injection volumes to test the hypothesis that a high formulation concentration (consequently, a lower injection volume) would increase bioavailability. After the first $2 \mathrm{mg} / \mathrm{kg} \mathrm{IM}$ study, the bioavailability was approximately $50 \%$. In order to attempt to attain concentrations comparable to the $3 \mathrm{mg} / \mathrm{kg}$ IV dose, the next two dogs were dosed at $6 \mathrm{mg} / \mathrm{kg}$. In total, three doses (1-,2- and 6-mg/kg) across four ALLO concentrations (3-, 6-, 11-, and 14$\mathrm{mg} / \mathrm{mL}$ ) were evaluated. Whole blood samples ( 2 to $5 \mathrm{~mL}$ ) were collected via a catheterized central vein at pre-dose and at 1-, 3-, 5-, 15-, 30-, 45-minutes, 1-, 2-, 4-, and 6-hours post-injection. A washout period of at least 1 week was used.

Intracranial EEG data were collected in the dog with electrodes implanted intracranially. Data were recorded for two IV doses (1-2 mg/kg) and one IM dose (1 $\mathrm{mg} / \mathrm{kg}$ ). Each collection period started the day before and finished the day immediately following study drug administration. Continuous iEEG data were collected with sampling rate of $250 \mathrm{~Hz}$ from four iEEG channels.

Allopregnanolone Assay Whole blood was collected in K3EDTA-containing purpletop vacutainer tubes and centrifuged for plasma separation. The red blood cells and plasma were be immediately frozen $\left(-80^{\circ} \mathrm{C}\right)$ until analysis. An ultra high-performance liquid chromatography-mass spectrometry (UPLC-MS/MS) method developed and validated at the UC Davis Bioanalysis and Pharmacokinetics Core Facility was used to measure total plasma ALLO concentrations (Zolkowska, Wu, and Rogawski 2018). 
Canine plasma was obtained commercially from BioreclamationIVT LLC and used as blank plasma standard and for dilution.

The range of linear quantification was from $15 \mathrm{ng} / \mathrm{mL}$ to $1500 \mathrm{ng} / \mathrm{mL}$. Lower limit of quantitation (LLOQ) was set at $15 \mathrm{ng} / \mathrm{mL}$. The quality control of the calibration curve was performed by passing the criteria set by the Bioanalytical Method Validation FDA Guidance for Industry (U.S. Department of Health and Human Services. et al. 2018). Dilution integrity for up to 5 -fold was confirmed. No significant interfering peaks with signal above LLOQ were observed in blank or experimental pre-dose plasma samples. The correlation coefficient ( $r$ ) in each run was at least 0.99 for Allopregnanolone, using a least-squares linear regression with a $1 / x$ weighting. The intra-batch precision across all concentrations and analytical runs ranged from $2.96 \%$ to $14.95 \%$, and the intra-batch accuracy ranged from $-17.33 \%$ to $3.54 \%$ (\%Dev). The inter-batch precision across all concentrations and analytical runs ranged from $6.05 \%$ to $10.57 \%$, and the inter-batch accuracy ranged from $-13.52 \%$ to $-0.18 \%(\% \mathrm{Dev})$.

PK Analysis and Simulations ALLO concentration-time data were analyzed using non-compartmental and compartmental analyses, including population approaches (Phoenix 64, Build 8.0.0.3176, Certara L.P., Princeton, NJ, USA). Concentrations below the lower limit of quantitation were treated as missing values. Pharmacokinetic parameters determined included maximum concentration $\left(\mathrm{C}_{\max }\right)$, time at which maximum concentration is achieved $\left(t_{\max }\right)$, and terminal half-life $\left(t_{1 / 2}\right)$. The area under the time-concentration curve $\left(A \cup C_{\infty}\right)$ was calculated using the equation (1), where $\mathrm{Cp}$ is the plasma ALLO concentration, $\mathrm{t}_{\text {last }}$ is the time at which the last plasma sample was 
drawn, $\mathrm{Cp}_{\text {last }}$ is the last measured plasma ALLO concentration, and $\mathrm{k}_{\mathrm{el}}$ is the terminal rate constant) and a linear-log trapezoidal method. The points used to calculate the terminal phase half-life were determined using the Phoenix algorithm which determines the best fit line via minimizing $r^{2}$. Percent extrapolated were less than $30 \%$ in all calculations except in one dog (Dog 3) following IM administration. A test for doseproportionality was conducted using a one-way ANOVA test across dose-normalized $\mathrm{AUC}_{\infty}$ and $\mathrm{C}_{\max }$ with the assumption of homoscedasticity.

IM bioavailability (F\%) was calculated using the equation (2), where the individual dog's $A U C_{\text {inf }}$ were used for each route. Clearance $(C L)$ and volume of distribution (V) were calculated using the equations (3) and (4), respectively. All plots were created using the GraphPad Prism 7 (Version 7.0a, GraphPad Software, Inc., La Jolla, CA, USA).

Population compartmental modeling was performed to characterize the IV concentration-time data (Phoenix Non-Linear Mixed Effects 8.0). First order conditional estimation extended least squares method was used throughout the model building process. A proportional error model for between-subject variability was used. Additive, multiplicative, and combined error models for residual unexplained variability were evaluated. The best fit model was determined using visual inspection, goodness of fit plots (e.g., conditional weighted residual plots and observed versus predicted), objective function value (OFV), Akaike's Information Criterion, and precision of model parameters. Simulations were conducted using parameter estimates generated from the population PK model in Phoenix NLME. 
In addition to calculating bioavailability via the standard method of dividing drug exposure (AUC, determined by NCA) following two routes of administration, bioavailability can be calculated as the cumulative fraction absorbed using deconvolution. Like the AUC/NCA method, deconvolution is based on the assumptions of the linear superposition principle (Rowland and Tozer 2011). Phoenix WinNonlin Deconvolution function was performed to determine the input rate following IM administration using individual PK parameters following IV administration as the exponential terms of the unit impulse function. Concentration-time data from the IM administration were used as the response function.

Equations:

$$
\begin{aligned}
& \text { (1) } A U C_{\infty}=A U C_{0-t_{\text {last }}}+A U C_{t_{\text {last }}-\infty}=\int_{0}^{t_{\text {last }}} C_{p} d t+\frac{C_{p_{\text {last }}}}{k_{e l}} \\
& \text { (2) } F(\%)=\left(\frac{A U C_{I M}}{A U C_{I V}}\right) \times\left(\frac{\text { Dose }_{I V}}{\text { Dose }_{I M}}\right) \times 100 \\
& \text { (3) } C L=\frac{\text { Dose } * F}{A U C_{\infty}} \\
& \text { (4) } C L=k_{e l} * V_{d}
\end{aligned}
$$

Intracranial Electroencephalography (iEEG) Analysis and PK-PD Modeling. iEEG data were analyzed using custom algorithms (Matlab version 2018b) for characterizing the temporal dynamics of iEEG power in spectral bands of interest (Delta $(1-3 \mathrm{~Hz})$, Theta $(>3-7 \mathrm{~Hz})$, Alpha $(>7-12 \mathrm{~Hz})$, Beta $(>12-25 \mathrm{~Hz})$, High Beta $(>20-25 \mathrm{~Hz}))$ as described previously (Kremen et al. 2017). Absolute and relative power spectral 
densities across frequency bands were used as the pharmacodynamic response. Absolute power density refers to the absolute power $\left(\mathrm{V}_{\mathrm{rms}}{ }^{2} / \mathrm{Hz}\right.$, where $\mathrm{V}_{\mathrm{rms}}$ is the rootmean-square voltage of the patient's iEEG), while relative power density refers to the percentage of power a frequency band (such as beta) compared to the sum of all frequency bands (delta, theta, alpha, and beta). Individualized PK parameters were estimated using a population approach as described in the previous section, fixed, then indirect-link Emax/Imax PD models were explored using equations (5) and (6). An indirect-link was used due to the hysteresis that was observed. The best fit model was determined using visual inspection and precision of model parameters. Equations:

$$
\begin{aligned}
& \text { (5) } \frac{d C_{e}}{d t}=k_{e 0} \cdot\left(C_{e}-C_{p}\right) \\
& \text { (6) } E=E_{0}+\frac{E_{m a x} \cdot C_{e}^{\gamma}}{E C_{50}^{\gamma}+C_{e}^{\gamma}}
\end{aligned}
$$

Safety and Behavioral Response Evaluations. A modified Glasgow coma scale (mGCS) was used to quantitate degree of sedation pre-dose and at scheduled blood sampling times (Supplemental Table 2). Cardiorespiratory activity (blood pressure, heart rate, and respiratory rate) was assessed at blood sampling times up to 30 minutes. In addition to sedation and vitals, the dogs were monitored for vomiting, diarrhea, and lethargy prior to and for 60 minutes after drug administration, and at each blood sampling time. Behavioral and iEEG activity were monitored by veterinary staff for seizure activity. As doses were escalated, the maximal tolerated toxicity, as determined by the supervising veterinarian, was defined as 20 minutes of sedation with stable cardiorespiratory activity (respiratory rate greater than 6 or less than $60 \mathrm{bpm}$, systolic 
blood pressure greater than $60 \mathrm{mmHg}$, heart rate greater than 50 or less than 160 bpm). The IM injection sites were examined for swelling, tenderness, and redness following drug administration.

\section{Results}

The demographics of the dogs are listed in Supplemental Table 1.

\section{Pharmacokinetics Following Intravenous Administration}

The concentration-time profiles following IV administration are shown in Figure 1. Pharmacokinetic parameter estimates from non-compartment analysis are presented in Table 2. On average, IV ALLO exhibits a relatively short terminal phase half-life of 10-30 mins and a large volume of distribution. One-way ANOVA tests across dose-normalized $\mathrm{AUC}_{\infty}$ and $\mathrm{C}_{\max }$ suggest IV ALLO exhibits proportionality with respect to dose within the dose range studied (Figure 2).

Using a population approach, a two-compartment model with first-order elimination and proportional error best fit the ALLO concentration data following IV (Supplemental Table 3 and Supplemental Figure 1). A random effect for volume of distribution was noninformative and therefore not included in the model. These parameter estimates were used to simulate plasma concentration-time profiles for dosing selection.

\section{Pharmacodynamics Following Intravenous Administration}


Across all iEEG frequency bands, absolute power density increased during and transiently after IV ALLO $1 \mathrm{mg} / \mathrm{kg}$ infusion (Figure 3). The amplitude and duration of these changes increased at the higher IV dose. Concentration-EEG data were best fit by indirect-link sigmoidal Emax models (Table 3, Figure 4). The delay equilibrium rate constants ranged between 1.3-5.1 $\mathrm{min}^{-1}$, corresponding to a delay equilibrium half-life of 8-30 seconds. The $\mathrm{EC}_{50}$ ranged between $270-700 \mathrm{ng} / \mathrm{mL}$ and was considerably lower for the beta frequency band, suggesting the beta frequency band is the most sensitive to ALLO. Its $\mathrm{EC}_{50}$ of $270 \mathrm{ng} / \mathrm{mL}$ in the theoretical effect compartment corresponds to $\sim 400 \mathrm{ng} / \mathrm{mL}$ in the plasma.

High beta frequency band $(20-25 \mathrm{~Hz})$ relative power density decreased, while alpha frequency band $(7-12 \mathrm{~Hz})$ relative power density increased during and transiently after IV infusion. As with absolute power density, relative power density increased in amplitude and duration following the $2 \mathrm{mg} / \mathrm{kg}$ infusion. Concentration-iEEG data for change in alpha and high beta frequency band relative power density were best fit by indirect-link sigmoidal Emax and Imax models, respectively. The delay equilibrium rate constants were $0.92-2.23 \mathrm{~min}^{-1}$, which correspond to delay equilibrium half-lives of 1945 seconds. The $\mathrm{EC}_{50}$ ranged between $329-759 \mathrm{ng} / \mathrm{mL}$ and were lower for the high beta frequency band. Its $\mathrm{EC}_{50}$ of $329 \mathrm{ng} / \mathrm{mL}$ in the theoretical effect compartment corresponded to $\sim 700 \mathrm{ng} / \mathrm{mL}$ in the plasma.

\section{Pharmacokinetics Following Intramuscular Administration}


The concentration-time profiles following IM administration are shown in Figure 5.

Following IM injection, there is an observed monoexponential decay in contrast to the biexponential decay following IV infusion, suggesting the presence of an absorptionlimited terminal phase.

Due to the vast differences in absorption kinetics following each IM injection, individual non-compartmental PK analysis was performed (Table 4). Based on the known drug disposition following IV administration, a two-compartment model with firstorder elimination, first-order absorption, and proportional error was used. There was an increasing trend in absorption rate with increasing formulation concentration, except at the $14 \mathrm{mg} / \mathrm{mL}$ formulation. The absorption rate from the $14 \mathrm{mg} / \mathrm{mL}$ formulation could not be estimated with precision, possibly because it was truly a zero-order absorption rate constant rather than first-order absorption rate constant. In contrast to IV administration, IM ALLO exhibits a terminal phase half-life ranging from 0.6-2.1 hours. There was an increasing trend in bioavailability with increasing formulation concentration and decreasing injection volume (Figure $6 \mathrm{~A}$ ). The absorption profiles appear to follow a firstorder absorption rate in most experiments (Figure 6B). At the highest formulation concentration tested (14 mg/mL), there appears to be zero-order absorption occurring, which raises concern for the possibility of agglomeration, crystallization, and/or precipitation of drug into muscle tissue.

\section{Pharmacodynamics Following Intramuscular Administration}

Across all iEEG frequency bands, there were statistically significant but minimal changes to absolute power densities (Supplemental Figure 2). As with absolute power 
density, decreases in high beta frequency band and increases in alpha frequency band were not as drastic as changes seen following IV infusion.

\section{Safety and Tolerability}

IV ALLO 1-3 mg/kg infused over 5 minutes and IM 1-2 mg/kg was shown to be safe and tolerable in dogs. There was a dose-dependent increase in ataxia and sedation (Table 5). At $4 \mathrm{mg} / \mathrm{kg} \mathrm{IV}$, dogs were immobile and briefly unarousable even with pain stimulation for 1-3 minutes with stable vital signs.

Following IV infusion, ataxia occurred within 1.5-3 minutes following infusion start for a duration of 10-18.5 minutes. In healthy dogs, onset of sedation occurred at 3.5-5 minutes following infusion start and lasted up to 6 minutes at doses greater than 2 $\mathrm{mg} / \mathrm{kg}$. The dog on chronic PB had greater sedation at $2 \mathrm{mg} / \mathrm{kg} \mathrm{IV}$, which was associated with higher plasma ALLO concentrations. There were no infusion site reactions observed.

Following IM injection, onset of ataxia without sedation occurred 3-5 minutes following the $6 \mathrm{mg} / \mathrm{kg}$ dose and lasted for 17-19 minutes. Of note, pain associated with injection volume was observed only at the $6 \mathrm{mg} / \mathrm{kg} \mathrm{IM}$ dose, and may have been associated with the volume infused (19.1-20.6 mL).

\section{Discussion}


Intravenous ALLO has a short terminal phase half-life and a moderately large volume of distribution in dogs (6-30 minutes, 2-6 L/kg). There was a rapid decrease in concentrations following IV administration. Given the large volume of distribution and lipophilic nature of this compound, this drop is likely due to redistribution. It is unlikely that these high concentrations immediately following dosing are the due to artificially high levels at the drug administration site as blood was sampled from an extremity different from that used for drug administration. Across the doses studied, IV ALLO exhibited linear pharmacokinetics with respect to dose. This information will be useful for instances where a manipulation of a target ALLO concentration or exposure (e.g., doubling the dose to double the exposure, up to $4 \mathrm{mg} / \mathrm{kg}$ ) may be necessary during clinical trials.

We found increases in absolute power spectral density across all frequency bands following IV ALLO, which is consistent to what has been reported following BZD administration. Increases in absolute and relative power density of the beta frequency band in response to BZD intervention have been widely cited (Mandema and Danhof 1992; Mandema, Kuck, and Danhof 1992; Greenblatt et al. 1989; Van Lier et al. 2004; Friedman et al. 1992). The beta frequency band appears to have highest sensitivity for plasma ALLO concentrations with $\mathrm{EC}_{50}$ values two-fold lower than other frequency bands.

In contrast to absolute power spectral density, IV ALLO results in a decrease in the relative power spectral density of the beta frequency band, while the alpha frequency 
band increased. Diazepam, on the other hand, elicits increases in relative power density of high beta (defined as $21-30 \mathrm{~Hz}$ ) while decreasing alpha (defined as $9-10 \mathrm{~Hz}$ ) in rats (Van Lier et al. 2004). This suggests that although ALLO and BZDs potentiate GABA $_{A}$ activity, they induce differential effects on EEG activity. This may be due to ALLO's activity at synaptic and extrasynaptic $\mathrm{GABA}_{\mathrm{A}}$ receptors and/or its ability to enhance the chloride channel opening duration and frequency (Greenfield 2013; Carver and Reddy 2013). BZDs only have activity at synaptic $\mathrm{GABA}_{A}$ receptors and increase chloride channel opening frequency (Greenfield 2013; Carver and Reddy 2013). The pharmacodynamic effect drops rapidly following administration in relation to ALLO plasma concentrations and fairly rapid half-life. However, it is unclear whether sustained drug exposure is necessary for seizure cessation. Previous rodent studies suggest that attaining a target concentrations briefly will likely be therapeutic (Zolkowska, Wu, and Rogawski 2018).

Zolkowska et al demonstrated that IM ALLO has great potential to be useful as a firstline treatment for SE, however, given the incomplete absorption, our current formulations are not ideal for a first-line canine SE treatment (Zolkowska, $\mathrm{Wu}$, and Rogawski 2018). Plasma concentrations following IM dosing were lower than expected compared to the same dose given IV. This observation is explained by the low absorption rates, which were dependent on formulation concentration and injection volume. 
By evaluating the PK across different doses and formulation strengths, we found that a higher formulation concentration was associated with a faster absorption rate. It has been noted that injection volume does have an inverse relationship with absorption rate for IM injections independent of the water solubility of the drug (Pfeffer and Van Harken 1981; Hirano, Ichihashi, and Yamada 1981). Other factors that may affect the absorption rate constant include the particle size, cohesiveness of the dissolved particles, initial injection concentration, injection speed and pressure, and the physiological state of the injection site (Hirano, Ichihashi, and Yamada 1981). We also observed that at the highest formulation concentration of $14 \mathrm{mg} / \mathrm{mL}$, the estimated absorption rate constant was not as high as we expected based on the formulationabsorption trend observed with previous formulations and appeared to follow a zeroorder rate. This suggests that $14 \mathrm{mg} / \mathrm{mL}$ may be too high of an initial injection concentration and may have resulted in possible agglomeration and/or precipitation of the drug. We observed that $11-14 \mathrm{mg} / \mathrm{mL}$ result in a near $100 \%$ bioavailability, however, additional studies with a larger sample size would be needed to verify this finding.

Simulations using the PK parameters from one dog (Supplemental Figure 3) suggest an $8 \mathrm{mg} / \mathrm{kg}$ IM dose would be necessary to achieve target plasma concentration window of $500-1000 \mathrm{ng} / \mathrm{mL}$ using a $6 \mathrm{mg} / \mathrm{mL}$ formulation. However, this would result in an unacceptably large injection volume ( $27 \mathrm{~mL}$ for a $20 \mathrm{~kg} \mathrm{dog}$ ), which would limit the absorption rate and cause pain upon injection similar in severity to what was observed at the $6 \mathrm{mg} / \mathrm{kg}$ dose. 
The largest limitation of the IM route of administration is the inability to attain high enough plasma concentrations to elicit iEEG changes. Strategies to increase plasma concentration using clinically-relevant volumes include but are not limited to: 1) increasing its water solubility by synthesizing a pro-drug or using alternative delivery systems; 2) using different administration strategies like multiple injections or changing the needle gauge and/or length; or 3) optimizing the formulation by using multiple solvents.

Based on studies done in a tetramethylenedisulfotetramine (TETS)-induced SE mouse model and diisopropyl fluorophosphate (DFP)-induced SE rat model, peak plasma ALLO concentrations ranging between $400-2000 \mathrm{ng} / \mathrm{mL}$ are expected to terminate BZDrefractory SE in at least $90 \%$ of animals (Zolkowska, Wu, and Rogawski 2018, 2020; Dhir, Wu, and Rogawski 2020). Therefore, compiling all of the PKPD and safety data from our study and what has been reported by Zolkowska et al and Dhir et al, we propose that a $2 \mathrm{mg} / \mathrm{kg}$ dose infused over 5 minutes is an appropriate starting dose to test as a first-line agent to treat canine SE, as this dose is predicted to attain the target concentrations (500-1000 ng/mL) without causing heavy sedation (Figure 7).

Alternatively, a $1 \mathrm{mg} / \mathrm{kg}$ bolus injection may also be sufficient to achieve the targeted $\mathrm{C}_{\max }$. In addition, a $1 \mathrm{mg} / \mathrm{kg} 5$ minute infusion would also attain plasma concentrations that fall within the range between the $\mathrm{EC}_{50}$ and those associated with heavy sedation, however, the $2 \mathrm{mg} / \mathrm{kg}$ infusion is predicted to attain the peak concentration observed in the TETS SE mouse study ( $900 \mathrm{ng} / \mathrm{mL}$ ) as early as 3 minutes into the start of infusion. 
One major limitation of the study is the small number of animals, as is the heterogeneity among the dogs. Furthermore, while sex differences may exist in the pharmacokinetics or pharmacodynamics of ALLO, we were unable to examine the differences due to the limited number of dogs ( 3 males and 2 females) in our study. Our study only included one animal on chronic PB, and one with a history of witnessed seizures. Given the small number of dogs in the study, it is not possible to conclude whether concurrent us of PB induces drug-drug interaction. However, for one heathy dog, daily PB dosing was added for 2 weeks prior to the study of ALLO and the pharmacokinetics of ALLO did not appear to be affected. Our results in combination with preclinical evidence of rapid onset of antiseizure activity suggest IV ALLO shows promise as a first-line treatment of canine SE given its rapid distribution to the brain, safety, and novel mechanism of action.

Future work includes evaluating of formulations suitable for IM delivery of ALLO and conducting a pilot study of IV ALLO in treatment of canine SE. If a canine SE clinical trial proves successful, not only could the results be used to further the development of ALLO as an alternative treatment for canine SE, but it could also inform clinical trial designs for the use of IV ALLO in treating SE in people.

\section{Acknowledgements}

We would like to acknowledge the American Epilepsy Society Pre-Doctoral Fellowship, American Foundation of Pharmaceutical Education Pre-Doctoral Fellowship, American Kennel Club Foundation, National Institutes of Health/National Institute of Neurological Disorders and Stroke (NIH/NINDS), and MacMillan Epilepsy Innovation Fund who 
funded this research. We also acknowledge and thank Andrea Eckert for her care of the animals and sample collection.

\section{Financial Disclosures}

No author has an actual or perceived conflict of interest with the contents of this article.

\section{Authorship Contributions}

Participated in research design: Vuu, Patterson, Leppik, Rogawski, Coles, and Cloyd Conducted experiments: Vuu, Patterson

Contributed new reagents or analytic tools: Wu, Zolkowska

Performed data analysis: Vuu, Kremen, Worrell, Coles

Wrote or contributed to the writing of the manuscript: Vuu, Patterson, Wu, Zolkowska, Leppik, Coles, Cloyd

\section{References}

Alldredge, Brian K, Alan M Gelb, S Marshal Isaacs, Megan D Corry, Faith Allen, SueKay Ulrich, Mildred D Gottwald, et al. 2001. "A Comparison of Lorazepam, Diazepam, and Placebo for the Treatment of Out-of-Hospital Status Epilepticus." $N$ Engl J Med 345 (9): 631-37.

https://www.nejm.org/doi/pdf/10.1056/NEJMoa002141.

Bateman, Shane W, and Joane M Parent. 1999. "Clinical Findings, Treatment, and Outcome of Dogs with Status Epilepticus or Cluster Seizures: 156 Cases (19901995)." J Am Vet Med Asso 215 (10): 1463-68. https://doi.org/10.23736/S03929590.16.03730-5. 
Belelli, Delia, Anna Casula, Alice Ling, and Jeremy J. Lambert. 2002. "The Influence of Subunit Composition on the Interaction of Neurosteroids with GABAA Receptors." Neuropharmacology 43 (4): 651-61. https://doi.org/10.1016/S0028-3908(02)001727.

Berendt, M., H. Høgenhaven, A. Flagstad, and M. Dam. 1999. "Electroencephalography in Dogs with Epilepsy: Similarities between Human and Canine Findings." Acta Neurologica Scandinavica 99 (5): 276-83. https://doi.org/10.1111/j.16000404.1999.tb00676.x.

Blades Golubovic, Susan, and John H. Rossmeisl. 2017. "Status Epilepticus in Dogs and Cats, Part 2: Treatment, Monitoring, and Prognosis." Journal of Veterinary Emergency and Critical Care 27 (3): 288-300. https://doi.org/10.1111/vec.12604.

Carver, Chase Matthew, and Doodipala Samba Reddy. 2013. "Neurosteroid Interactions with Synaptic and Extrasynaptic GABAA Receptors: Regulation of Subunit Plasticity, Phasic and Tonic Inhibition, and Neuronal Network Excitability." Psychopharmacology. https://doi.org/10.1007/s00213-013-3276-5.

Chen, James Wy, and Claude G Wasterlain. 2006. "Status Epilepticus: Pathophysiology and Management in Adults." The Lancet Neurology 5 (3): 246-56. https://doi.org/10.1016/S1474-4422(06)70374-X.

DeLorenzo, Robert J, John M Pellock, Alan R Towne, and Jane G Boggs. 1995. "Epidemiology of Status Epilepticus." Clin Neurophys, 316-25.

Dhir, Ashish, Donald A Bruun, Michelle Guignet, Yi-Hua Tsai, Eduardo González, Jonas Calsbeek, Joan Vu, et al. 2020. "Allopregnanolone and Perampanel as Adjuncts to Midazolam for Treating Diisopropylfluorophosphate-Induced Status Epilepticus in 
Rats." Ann. N.Y. Acad. Sci 1480 (1): 183-206. https://doi.org/10.1111/nyas.14479. Dhir, Ashish, Chun-Yi Wu, and Michael A. Rogawski. 2020. "Antiseizure Effect of High

Dose Allopregnanolone in a Rat Diisopropyl Fluorophosphate Model of

Benzodiazepine-Refractory Status Epilepticus." American Epilepsy Society Annual Meeting Abs.552.

Falco-Walter, Jessica, and Thomas Bleck. 2016. "Treatment of Established Status Epilepticus." Journal of Clinical Medicine 5 (5): 49.

https://doi.org/10.3390/jcm5050049.

Friedman, H., David J. Greenblatt, Gary R. Peters, Carl M. Metzler, Melody D. Charlton, Jerold S. Harmatz, Edward J. Antal, Elmer C. Sanborn, and Steven F. Francom. 1992. "Pharmacokinetics and Pharmacodynamics of Oral Diazepam: Effect of Dose, Plasma Concentration, and Time." Clinical Pharmacology \& Therapeutics 52 (2): 139-50. https://doi.org/10.1038/clpt.1992.123.

Frye, C A. 1995. "The Neurosteroid 3alpha-,5alpha-THP Has Antiseizure and Possible Neuroprotective Effects in an Animal Model of Epilepsy." Brain Research 696: 11320. https://pdf.sciencedirectassets.com/271080/1-s2.0-S0006899300X00364/1s2.0-000689939500793P/main.pdf?X-Amz-SecurityToken=AgoJb3JpZ2luX2VjEMP\%2F\%2F\%2F\%2F\%2F\%2F\%2F\%2F\%2F\%2FwEa CXVzLWVhc3QtMSJHMEUCIGY1VIPNEZdnOOCwySxnnCa8rv3GVwJboOUo2JA hDIpUAiEAwGC7xa\%2FhNil.

Glauser, Tracy, Shlomo Shinnar, David Gloss, Brian Alldredge, Ravindra Arya, Jacquelyn Bainbridge, Mary Bare, et al. 2016. "Evidence-Based Guideline: Treatment of Convulsive Status Epilepticus in Children and Adults: Report of the 
Guideline Committee of the American Epilepsy Society." Epilepsy Currents 16 (1):

48-61. https://www.ncbi.nlm.nih.gov/pmc/articles/PMC4749120/pdf/i1535-7511-161-48.pdf.

Greenblatt, D J, B L Ehrenberg, J Gunderman, A Locniskar, J M Scavone, J S Harmatz, and R I Shader. 1989. "Pharmacokinetic and Electroencephalographic Study of Intravenous Diazepam, Midazolam, and Placebo." Clinical Pharmacology and Therapeutics 45 (4): 356-65. https://doi.org/10.1016/0278-2391(89)90742-8.

Greenfield, L John. 2013. "Molecular Mechanisms of Antiseizure Drug Activity at GABAA Receptors." Seizure: European Journal of Epilepsy 22: 589-600. https://doi.org/10.1016/j.seizure.2013.04.015.

Irwin, Ronald W., Christine M. Solinsky, Carlos M. Loya, Francesco G. Salituro, Kathleen E. Rodgers, Gerhard Bauer, Michael A. Rogawski, and Roberta Diaz Brinton. 2015. "Allopregnanolone Preclinical Acute Pharmacokinetic and Pharmacodynamic Studies to Predict Tolerability and Efficacy for Alzheimer's Disease." PLOS ONE 10 (6): e0128313. https://doi.org/10.1371/journal.pone.0128313.

Kapur, Jaideep. 2000. "Hippocampal Neurons Express GABA, Receptor Insensitive to Diazepam in Hyperexcitable Conditions." Epilepsia 41: 86-89.

Kokate, T G, A L Cohen, E Karp, and M A Rogawski. 1996. "Neuroactive Steroids Protect Against Pilocarpine-and Kainic Acid-Induced Limbic Seizures and Status Epilepticus in Mice." Neuropharmacology 35 (8): 1049-56. https://ac-els-cdncom.ezp1.lib.umn.edu/S0028390896000214/1-s2.0-S0028390896000214main.pdf?_tid=854e0bf8-152e-11e8-90b0- 
00000aacb361\&acdnat=1519015207_60d506a74297b6578f565971fd74647d.

Kremen, Vaclav, Benjamin H Brinkmann, Inyong Kim, Hari Guragain, Mona Nasseri, Abigail L Magee, Tal Pal Attia, et al. 2018. “Integrating Brain Implants With Local and Distributed Computing Devices: A Next Generation Epilepsy Management System." IEEE Journal of Translational Engineering in Health and Medicine 6: 2500112. https://doi.org/10.1109/JTEHM.2018.2869398.

Kremen, Vaclav, Juliano J Duque, Benjamin H Brinkmann, Brent M Berry, Michal T

Kucewicz, Fatemeh Khadjevand, Jamie Van Gompel, et al. 2017. "Behavioral State Classification in Epileptic Brain Using Intracranial Electrophysiology HHS Public Access." J Neural Eng 14 (2): 26001. https://doi.org/10.1088/1741-2552/aa5688. Lier, Hester Van, Wilhelmus H I M Drinkenburg, Yvonne J W Van Eeten, and Anton M L Coenen. 2004. "Effects of Diazepam and Zolpidem on EEG Beta Frequencies Are Behavior-Specific in Rats." Neuropharmacology 47: 163-74. https://doi.org/10.1016/j.neuropharm.2004.03.017.

Luisi, S., F. Petraglia, C. Benedetto, R. E. Nappi, F. Bernardi, M. Fadalti, F. M. Reis, M. Luisi, and A. R. Genazzani. 2000. "Serum Allopregnanolone Levels in Pregnant Women: Changes during Pregnancy, at Delivery, and in Hypertensive Patients." The Journal of Clinical Endocrinology \& Metabolism 85 (7): 2429-33. https://doi.org/10.1210/jcem.85.7.6675.

Mandema, Jaap W, and Meindert Danhof. 1992. "Electroencephalogram Effect Measures and Relationships Between Pharmacokinetics and Pharmacodynamics of Centrally Acting Drugs." Clin Pharmacokinet 23 (3): 191-215.

Mandema, Jaap W, Maarten T Kuck, and Meindert Danhof. 1992. "Differences in 
Intrinsic Efficacy of Benzodiazepines Are Reflected in Their Concentration-EEG Effect Relationship." Br. J. Pharmacol 105: 164-70.

https://www.ncbi.nlm.nih.gov/pmc/articles/PMC1908634/pdf/brjpharm002240168.pdf.

Naylor, David E, Hantao Liu, and Claude G Wasterlain. 2005. "Trafficking of GABA A Receptors, Loss of Inhibition, and a Mechanism for Pharmacoresistance in Status Epilepticus." The Journal of Neuroscience 25 (34): 7724-33.

https://doi.org/10.1523/JNEUROSCI.4944-04.2005.

Patterson, Edward E, Ilo E Leppik, Lisa D Coles, Michael Podell, Charles H Vite, William Bush, and James C Cloyd. 2015. "Canine Status Epilepticus Treated with Fosphenytoin: A Proof of Principle Study." Epilepsia 56 (6): 882-87. https://doi.org/10.1111/epi.12994.

Potschka, Heidrun, Andrea Fischer, Eva Lotta Von Rüden, Velia Hülsmeyer, and Wolfgang Baumgärtner. 2013. "Canine Epilepsy as a Translational Model?" Epilepsia 54 (4): 571-79. https://doi.org/10.1111/epi.12138.

Rogawski, Michael A., Carlos M. Loya, Kiran Reddy, Dorota Zolkowska, and Christoph Lossin. 2013. "Neuroactive Steroids for the Treatment of Status Epilepticus." Epilepsia 54 (SUPPL. 6): 93-98. https://doi.org/10.1111/epi.12289.

Saito, Miyoko, Karen R Muñana, Nicholas JH Sharp, and Natasha J Olby. 2001. "Risk Factors for Development of Status Epilepticus in Dogs with Idiopathic Epilepsy and Effects of Status Epilepticus on Outcome and Survival Time: 32 Cases (19901996)." J Am Vet Med Asso 219 (5): 618-23. https://avmajournals-avmaorg.ezp1.lib.umn.edu/doi/pdf/10.2460/javma.2001.219.618. 
Silbergleit, Robert, Valerie Durkalski, Daniel Lowenstein, Robin Conwit, Arthur Pancioli, Yuko Palesch, William Barsan, and NETT Investigators. 2012. "Intramuscular versus Intravenous Therapy for Prehospital Status Epilepticus." The New England Journal of Medicine 366 (7): 591-600. https://doi.org/10.1056/NEJMoa1005372.

Timby, Erika, Matts Balgard, Sigrid Nyberg, Olav Spigset, Agneta Andersson, Joanna Porankiewicz-Asplund, Robert H Purdy, Di Zhu, Torbjorn Backstrom, and Inger Sundström-Poromaa. 2006. "Pharmacokinetic and Behavioral Effects of Allopregnanolone in Healthy Women." Psychopharmacology 186: 414-24. https://doi.org/10.1007/s00213-005-0148-7.

Treiman, David M, Patti D Meyers, Nancy Y Walton, Joseph F Collins, Cindy Colling, A James Rowan, Adrian Handforth, et al. 1998. "A Comparison of Four Treatments for Generalized Convulsive Status Epilepticus." The New England Journal of Medicine 339 (12): 792-98.

https://www.nejm.org/doi/pdf/10.1056/NEJM199809173391202.

Trinka, Eugen, Hannah Cock, Dale Hesdorffer, Andrea O. Rossetti, Ingrid E. Scheffer, Shlomo Shinnar, Simon Shorvon, and Daniel H. Lowenstein. 2015. "A Definition and Classification of Status Epilepticus - Report of the ILAE Task Force on Classification of Status Epilepticus." Epilepsia 56 (10): 1515-23. https://doi.org/10.1111/epi.13121.

U.S. Department of Health and Human Services., Food and Drug Administration., Center for Drug Evaluation and Research., and Center for Veterinary Medicine. 2018. "Bioanalytical Method Validation: Guidance for Industry." http://www.fda.gov/Drugs/GuidanceComplianceRegulatorylnformation/Guidances/d 
efault.htmand/orhttp://www.fda.gov/AnimalVeterinary/GuidanceComplianceEnforce ment/GuidanceforIndustry/default.htm.

Zolkowska, Dorota, Chun-Yi Wu, and Michael A. Rogawski. 2020. "Antiseizure Activity of Intravenous Bolus Allopregnanolone in Mice and Rats." American Epilepsy Society Annual Meeting Abs.890.

Zolkowska, Dorota, Chun-Yi Wu, and Michael A Rogawski. 2018. "Intramuscular Allopregnanolone and Ganaxolone in a Mouse Model of Treatment-Resistant Status Epilepticus." Epilepsia 59 (supp 2): 1-8. https://doi.org/10.1111/epi.13999.

ZULRESSO $\square$ [package insert]. 2019. "ZULRESSO $\square$ [Package Insert]." Cambridge, MA. https://www.accessdata.fda.gov/drugsatfda_docs/label/2019/211371lbl.pdf.

\section{Footnotes}

a) This work was supported by the American Epilepsy Society Pre-doctoral Fellowship, American Foundation of Pharmaceutical Education Pre-doctoral Fellowship, American Kennel Club Foundation [grant \#02133], NIH/NINDS R21[NS072166], and MacMillan Epilepsy Innovation Fund

b) Thesis:

Vuu, Irene. (2019). Development of Parenteral Drugs for the Treatment of

Seizure Emergencies. Retrieved from the University of Minnesota Digital Conservancy, https://hdl.handle.net/11299/209019.

Poster Abstracts:

Vuu I, Coles LD, Wu C-Y, et al. Allopregnanolone PharmacokineticPharmacodynamic Modeling in Dogs with Naturally-Occurring Epilepsy. London- 
Innsbruck Colloquium on Status Epilepticus and Acute Seizures, London, United Kingdom. April 2019.

Vuu I, Coles LD, Leppik IE, et al. Intramuscular versus Intravenous Allopregnanolone Pharmacokinetics and Safety in Dogs for Early Treatment of Status Epilepticus. American Epilepsy Society Annual Conference, New Orleans, LA, December 2018; University of Minnesota Rare Disease Day, Minneapolis, MN, March 2019.

Vuu I, Coles LD, Leppik IE, et al. Intravenous Allopregnanolone for Treatment of Status Epilepticus: Safety and Pharmacokinetics. American Society for Experimental NeuroTherapeutics, Rockville, MD. March 2018.

Vuu I, Coles LD, Leppik IE, et al. Characterization of Allopregnanolone Pharmacokinetics in Dogs with Naturally-Occurring Epilepsy to Support Use in the Initial Treatment of Status Epilepticus. London-Innsbruck Colloquium on Status Epilepticus and Acute Seizures, Salzburg, Austria. April 2017.

c) Reprint requests may be sent to:

Lisa D Coles, MS, PhD, University of Minnesota College of Pharmacy, Experimental \& Clinical Pharmacology 4-214 McGuire Translational Research 2001 6th St SE Minneapolis, MN 55455 durh0016@umn.edu 
d) ${ }^{1}$ Clinical Pharmacology Modeling and Simulation, Amgen Inc, Thousand Oaks, CA

${ }^{2}$ Department of Veterinary Clinical Sciences, University of Minnesota College of $\begin{array}{llll}\text { Veterminary } & \text { Medicine, } & \text { Saint } & \text { Paul, }\end{array}$ ${ }^{3}$ Department of Neurology, University of California Davis School of Medicine, Sacramento, ${ }^{4}$ Department of Experimental and Clinical Pharmacology, University of Minnesota College of $\quad$ Pharmacy, $\quad$ Minneapolis, $\quad$ MN ${ }^{5}$ Department of Neurology, Mayo Clinic, Rochester, MN 


\section{Legends for Figures}

Figure 1: Plasma ALLO concentration-time profiles following 1-4 mg/kg ALLO infused IV over 5 minutes. There was a total of 11 IV infusions (3@1 mg/kg, $4 @ 2$ mg/kg, $2 @ 3$ mg/kg, 2 @ 4 mg/kg), PB: temporary PB; cPB: chronic PB.

Figure 2: Dose-normalized A) $\mathrm{AUC}_{\infty}$ and B) $\mathrm{C}_{\max }$ across 4 IV doses on a logarithmic scale. Mean values are shown with standard deviations. P-values were generated using one-way ANOVA tests $(\mathrm{n}-1$ groups $=3$, degrees of freedom $=7$ ) assuming homoschedasticity.

Figure 3: Time versus observed iEEG absolute power density $\left(\mathrm{V}^{2}{ }_{\mathrm{rms}} / \mathrm{Hz}\right)$ cross four frequency bands (delta [blue], theta [red], alpha [green], beta [purple]) and concentration (dashed black line) following A) 1- and B) 2-mg/kg IV infusions in one dog on PB. Time versus observed iEEG relative power density across alpha (green line) and high beta (purple line) frequency bands and concentration (dashed black line) following C) 1- and D) 2-mg/kg IV infusions in one dog on PB.

Figure 4a: iEEG effect-concentration profiles following 1-2 $\mathrm{mg} / \mathrm{kg}$ infused IV over 5 minutes (red and blue, respectively) and $1 \mathrm{mg} / \mathrm{kg}$ injected IM as a bolus (orange) in 1 dog on PB. Effect compartment concentrations are predicted using an indirect-link between PK and sigmoidal Emax PD models. IPRED: predicted effect; DV: observed effect 
Figure 4b:

iEEG (relative power density) effect-concentration profiles following $1-2 \mathrm{mg} / \mathrm{kg}$ infused IV over 5 minutes (red and blue, respectively) and $1 \mathrm{mg} / \mathrm{kg}$ injected IM as a bolus (orange) in 1 dog on PB. Effect compartment concentrations are predicted using an indirect-link between PK and sigmoidal Emax/Imax PD models. Colored circles are observed data; solid lines represent predicted data. IPRED: predicted effect; DV: observed effect.

Figure 5: Plasma ALLO concentration-time profiles $1-6 \mathrm{mg} / \mathrm{kg}$ injected IM as a bolus. There was a total of 5 IM injections (1@1 mg/kg, $2 @ 2$ mg/kg, $2 @ 6$ mg/kg).

Figure 6: A) IM bioavailability as a function of injection concentration. Each circle represents a different experiment (different dog/dose/injection concentration). Total injection volume, individual dog and dose are labeled by the corresponding circle. B) Cumulative fraction absorbed as a function of time. Each line represents a different experiment.

Figure 7: Simulations following 5-minute IV infusions at four doses. Simulations were generated using population PK parameter values. Dashed line denotes the plasma concentration associated with heavy sedation. Dotted line denotes the plasma concentration associated to the $\mathrm{EC}_{50}$ in the theoretical effect compartment. 


\section{Tables}


Table 1. Number of

\begin{tabular}{|c|c|c|c|c|c|c|c|c|c|}
\hline Route & \multicolumn{4}{|c|}{ IV Studies } & \multicolumn{5}{|c|}{ IM Studies } \\
\hline Dose (mg/kg) & 1 & 2 & 3 & 4 & 1 & & 2 & & 6 \\
\hline Formulation ( $\mathrm{mg} / \mathrm{mL})$ & \multicolumn{4}{|c|}{6} & 11 & 3 & 6 & 14 & 6 \\
\hline Number of Dogs (total) & 4 & 4 & 2 & 2 & 1 & 1 & 1 & 1 & 2 \\
\hline Number of Dogs on PB & 2 & 2 & 0 & 0 & 1 & \multicolumn{3}{|c|}{0} & 0 \\
\hline Number of Studies in Dog with iEEG & 1 & 1 & 0 & 0 & 1 & \multicolumn{3}{|c|}{0} & 0 \\
\hline
\end{tabular}

Animals per Study Dose and Route 
Table 2. Noncompartmental PK Parameter Estimates Following IV Administration

\begin{tabular}{|c|c|c|c|c|c|c|c|}
\hline $\begin{array}{l}\text { Dose } \\
(\mathrm{mg} / \mathrm{kg})\end{array}$ & $n$ & $\begin{array}{l}C_{\max } \\
(\mathrm{ng} / \mathrm{mL})\end{array}$ & $\begin{array}{l}\lambda_{z} \\
\left(h r^{-1}\right)\end{array}$ & $\begin{array}{l}t_{1 / 2} \\
(h r)\end{array}$ & $\begin{array}{l}C L \\
(L / h r / k g)\end{array}$ & $\begin{array}{l}V \\
(\mathrm{~L} / \mathrm{kg})\end{array}$ & $\begin{array}{l}A \cup C_{\infty} / \text { Dose } \\
\left(\mathrm{ng} / \mathrm{mL}^{*} \mathrm{hr} /(\mathrm{ng} / \mathrm{kg})\right) \\
\times 10^{-5}\end{array}$ \\
\hline 1 & $\begin{array}{c}2 \\
(1)\end{array}$ & $425-1340$ & $\begin{array}{c}7.2-8.1 \\
(3.6)\end{array}$ & $\begin{array}{c}0.09-0.10 \\
(0.2)\end{array}$ & $\begin{array}{c}16.0-20.1 \\
(7.2)\end{array}$ & $\begin{array}{l}2.0-2.7 \\
(2.0)\end{array}$ & $\begin{array}{c}49.8-62.5 \\
(139.8)\end{array}$ \\
\hline 2 & $\begin{array}{c}3 \\
(1)\end{array}$ & $1654-5287$ & $\begin{array}{c}1.2-4.0 \\
(1.8)\end{array}$ & $\begin{array}{l}0.19-0.56 \\
(0.4)\end{array}$ & $\begin{array}{c}7.4-13.7 \\
(3.4)\end{array}$ & $\begin{array}{c}2.6-6.0 \\
(1.9)\end{array}$ & $\begin{array}{c}72.9-134.8 \\
(295.8)\end{array}$ \\
\hline 3 & 2 & $2440-4661$ & 2.1-2.3 & $0.31-0.33$ & $7.9-9.5$ & $3.5-4.5$ & $105.6-126.3$ \\
\hline 4 & 2 & $3660-5172$ & $1.4-1.7$ & $0.40-0.50$ & $6.0-9.9$ & $4.2-5.6$ & $100.8-167.9$ \\
\hline
\end{tabular}

Estimates are presented as a range. Values in parentheses are from one dog on chronic PB. $\mathrm{C}_{\max }$ : maximum observed plasma concentration; $\lambda_{z}$ : terminal rate constant; $t_{1 / 2}$ : terminal halflife; $\mathrm{CL}$ : clearance; $\mathrm{V}$ : volume of distribution; $\mathrm{AUC}_{\infty} /$ Dose: dose-normalized area under the concentration-time curve from time 0 extrapolated to infinity 
Table 3. PKPD Parameter Estimates Associated with IV Infusions

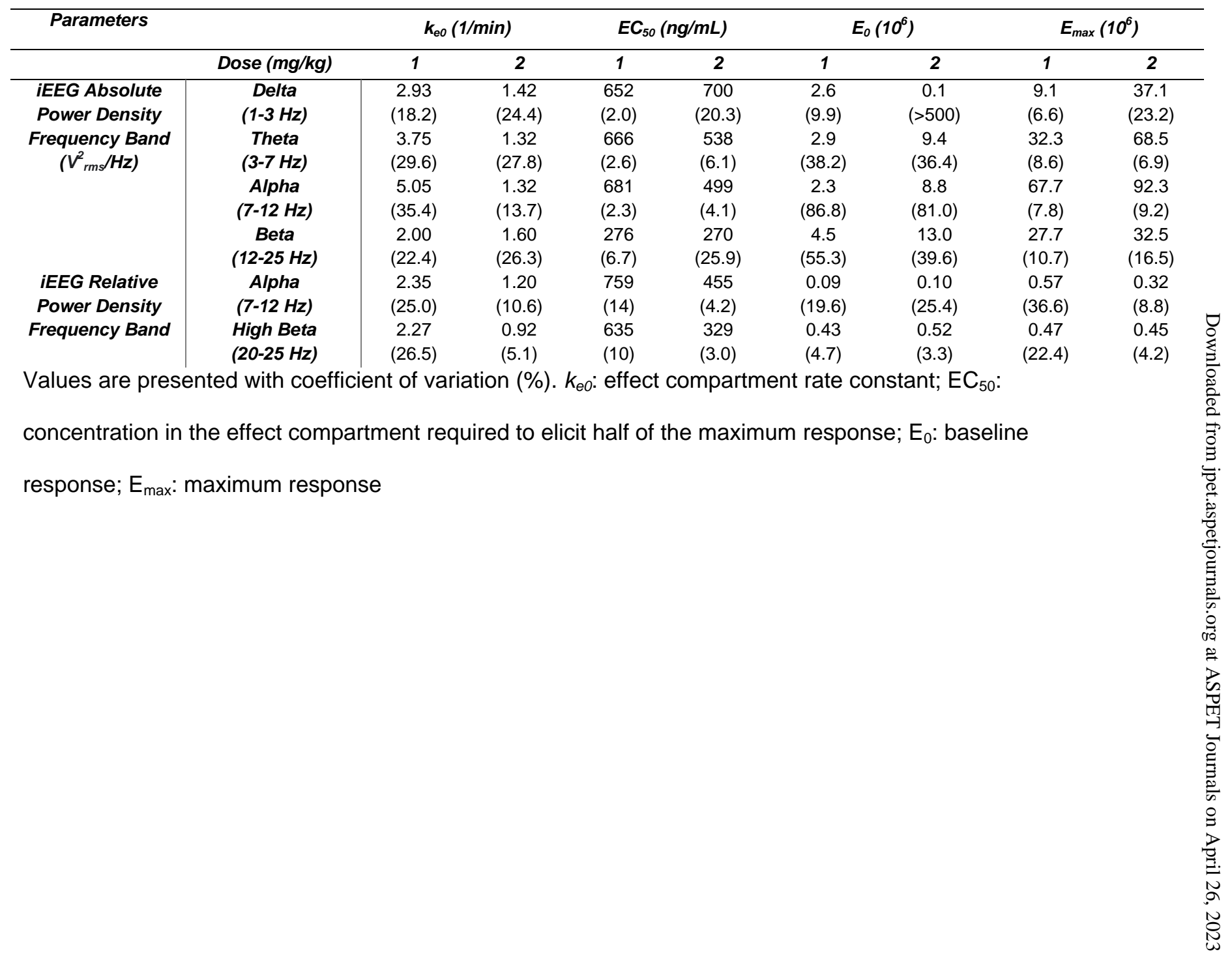


Table 4. Noncompartmental PK Parameter Estimates Following IM Administration

\begin{tabular}{|c|c|c|c|c|c|c|c|c|c|c|c|}
\hline $\begin{array}{l}\text { Form. } \\
\text { (mg/mL) }\end{array}$ & $\begin{array}{l}\text { Dose } \\
(\mathrm{mg} / \mathrm{kg})\end{array}$ & $\begin{array}{l}\text { Inj. Vol } \\
(m L)\end{array}$ & $n$ & $\begin{array}{l}t_{\max } \\
(\min )\end{array}$ & $\begin{array}{l}C_{\max } \\
(\mathrm{ng} / \mathrm{mL})\end{array}$ & $\begin{array}{l}\lambda_{z} \\
\left(h r^{-1}\right)\end{array}$ & $\begin{array}{l}t_{1 / 2} \\
\text { (hr) }\end{array}$ & $\begin{array}{l}C L / F \\
(L / h r / k g)\end{array}$ & $V / F(L / k g)$ & $\begin{array}{l}A U C_{\infty} / \\
\text { Dose } \\
\left(\mathrm{ng} / \mathrm{mL} L^{*} \mathrm{hr} /(\mathrm{ng}\right. \\
/ \mathrm{kg})) \times 10^{-5}\end{array}$ & $\begin{array}{l}F \\
(\%)\end{array}$ \\
\hline 3 & 2 & 13 & 1 & 5 & 94 & 0.50 & 1.4 & 11.4 & 22.9 & 8.78 & 54 \\
\hline 6 & 2 & 6.5 & 1 & 3 & 328 & 1.23 & 0.56 & 10.1 & 8.2 & 9.86 & 61 \\
\hline 6 & 6 & $\begin{array}{l}19.1- \\
20.6\end{array}$ & 2 & $3-10$ & $323-877$ & $\begin{array}{l}0.27- \\
0.60\end{array}$ & $1.2-2.5$ & $9.5-12.2$ & $15.9-44.7$ & $8.19-10.5$ & $65-67$ \\
\hline 11 & 1 & 1.5 & $1^{*}$ & 15 & 205 & 1.25 & 0.56 & 6.0 & 4.8 & 16.6 & 98 \\
\hline 14 & 2 & 2.1 & 1 & 10 & 53 & 0.32 & 2.13 & 5.1 & 15.8 & 19.5 & 120 \\
\hline
\end{tabular}

Estimates are presented as a range. $\left({ }^{*}\right)$ denotes the dog on chronic PB. Form.: formulation concentration; Inj. Vol.: injection volume; $t_{\max }$ : time at maximum concentration; $\mathrm{C}_{\max }$ : maximum observed plasma concentration; $\lambda_{z}$ : terminal rate constant; $t_{1 / 2}$ : terminal half-life; $C L / F$ : apparent clearance; V/F: apparent volume of distribution; $\mathrm{AUC}_{\propto} / \mathrm{Dose}$ : dose-normalized area under the concentration-time curve from time 0 extrapolated to infinity; F: bioavailability 
Table 5. Ataxia and Sedation

\begin{tabular}{|c|c|c|c|c|c|c|c|c|c|}
\hline Route & $\begin{array}{l}\text { Dose } \\
(\mathrm{mg} / \mathrm{kg})\end{array}$ & $n$ & $\begin{array}{l}C_{\max } \\
(\mathrm{ng} / \mathrm{mL})\end{array}$ & Ataxia & Sedation & $\begin{array}{l}\text { Onset of } \\
\text { Ataxia } \\
\text { (min) }\end{array}$ & $\begin{array}{l}\text { Duration of } \\
\text { Ataxia } \\
\text { (min) }\end{array}$ & $\begin{array}{l}\text { Onset of } \\
\text { Sedation } \\
\text { (min) }\end{array}$ & $\begin{array}{l}\text { Duration } \\
\text { Sedation } \\
\text { (min) }\end{array}$ \\
\hline \multirow[t]{4}{*}{$I V$} & 1 & 3 & $425-1340$ & $33 \%$ & $0 \%$ & 3 & 6 & & \\
\hline & 2 & 4 & $1654-5287$ & $100 \%$ & $25 \%$ & $1.5-2$ & $10-16$ & 3.5 & 10 \\
\hline & 3 & 2 & $2440-4661$ & $100 \%$ & $50 \%$ & $1.5-3$ & $13-13.5$ & 3.5 & 4.5 \\
\hline & 4 & 2 & $3660-5172$ & $100 \%$ & $100 \%$ & 1.5 & $15.5-18.5$ & $4.5-5$ & $5-6$ \\
\hline \multirow[t]{3}{*}{$I M$} & 1 & 1 & 205 & $0 \%$ & $0 \%$ & & & & \\
\hline & 2 & 2 & $53-328$ & $0 \%$ & $0 \%$ & & & & \\
\hline & 6 & 2 & $323-877$ & $100 \%$ & $0 \%$ & $3-5$ & $17-19$ & & \\
\hline
\end{tabular}

Estimates are presented in ranges and percentage of animals. $\mathrm{C}_{\max }$ : maximum observed concentration. 
Figure 1. Plasma ALLO Concentration-Time Profiles Following IV Administration

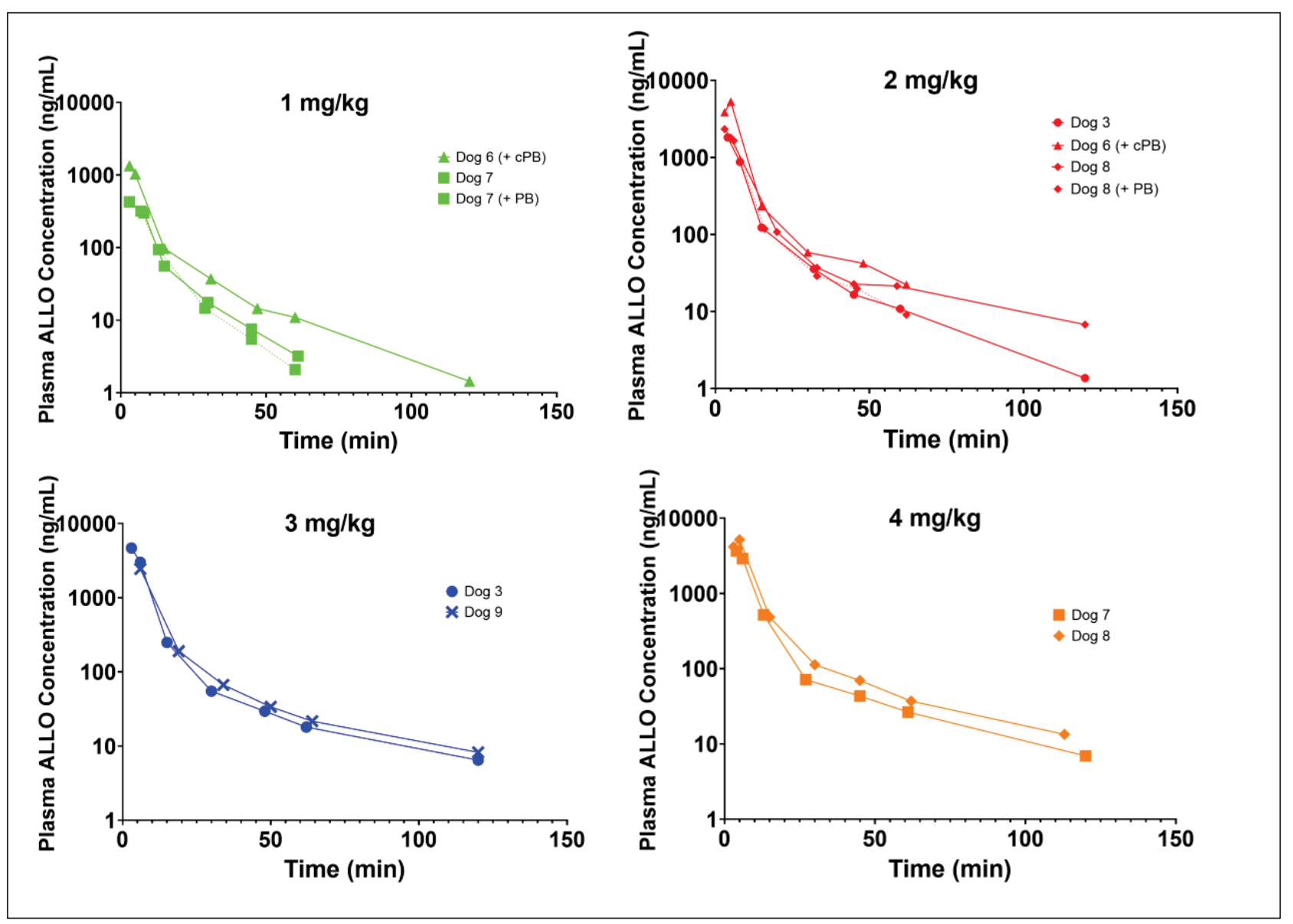


Figure 2. Dose Proportionality of $A U C_{\infty}$ and $C_{\max }$

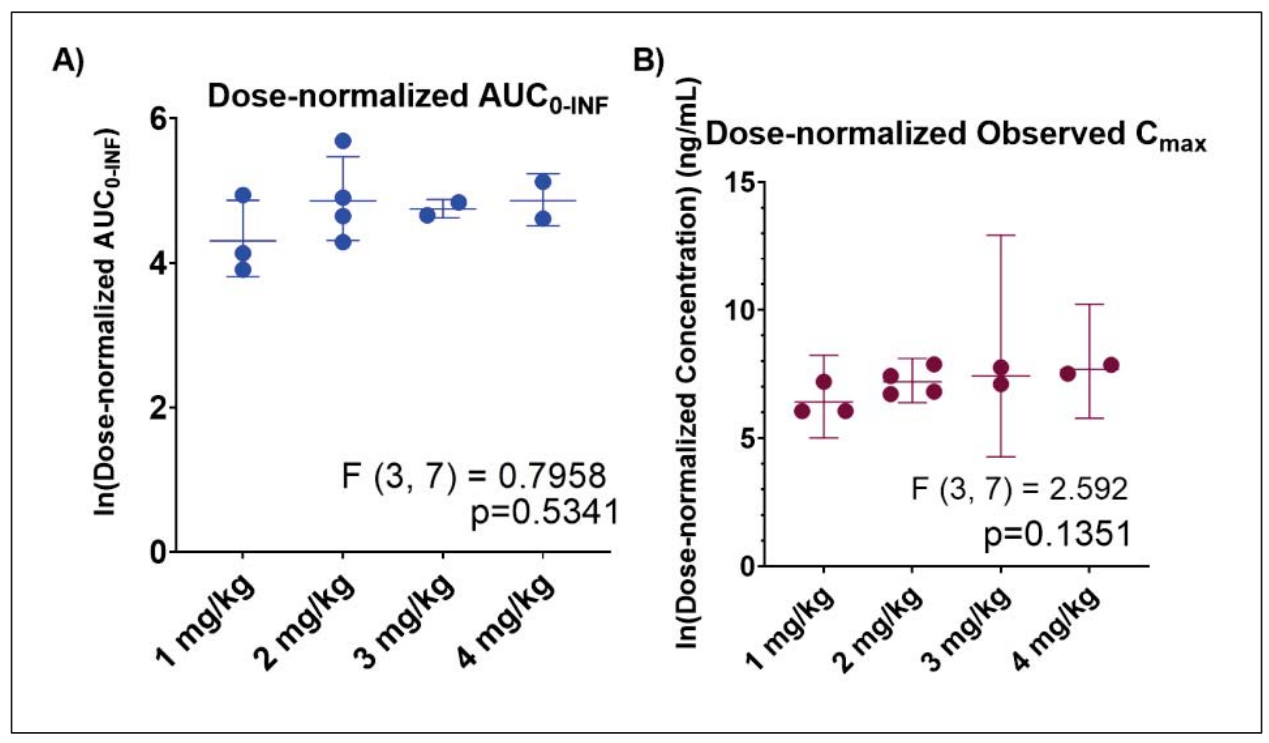


Figure 3. Time versus Concentration and iEEG Absolute and Relative Power Densities

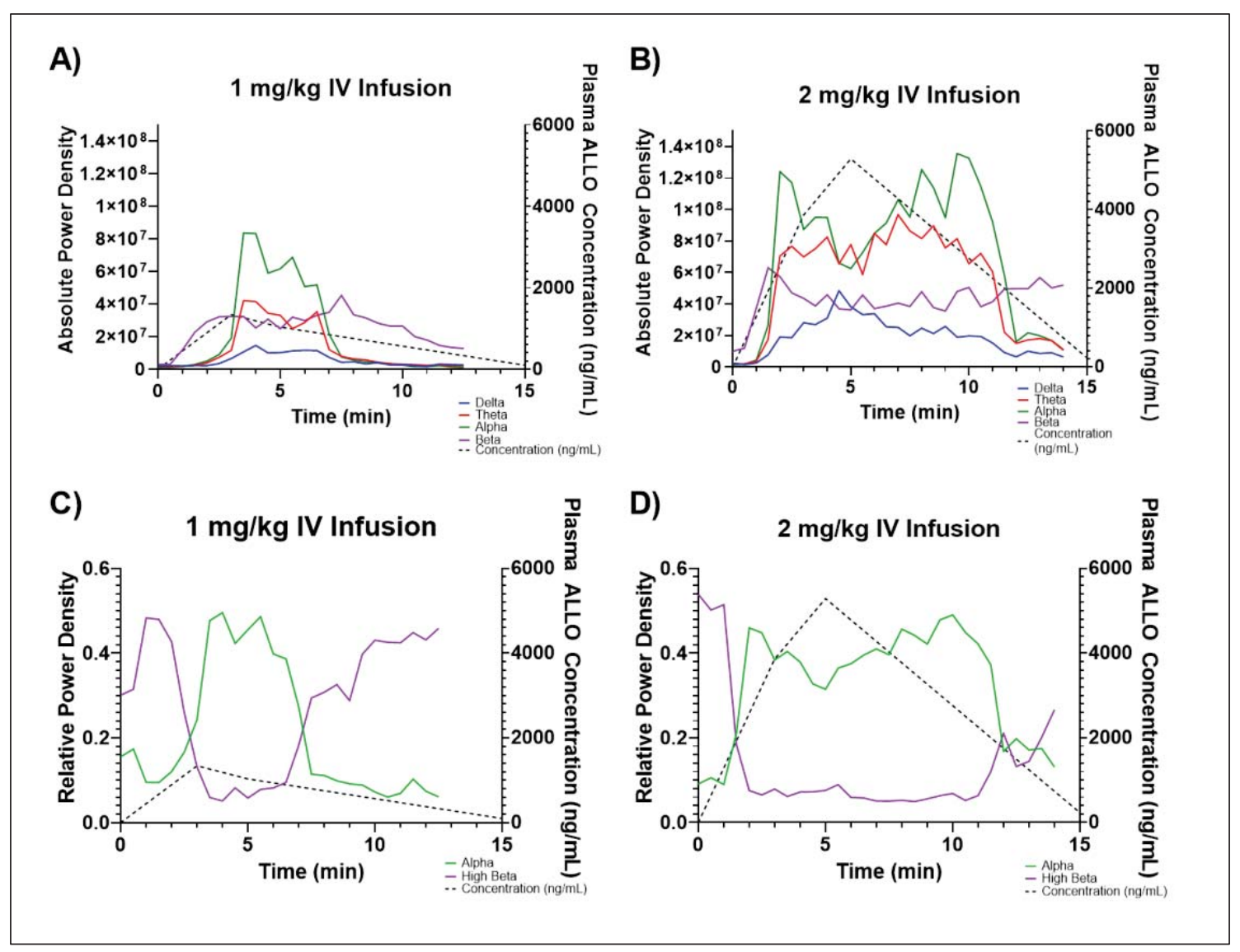


Figure 4a. iEEG Absolute Power Density Effect-Concentration Profiles

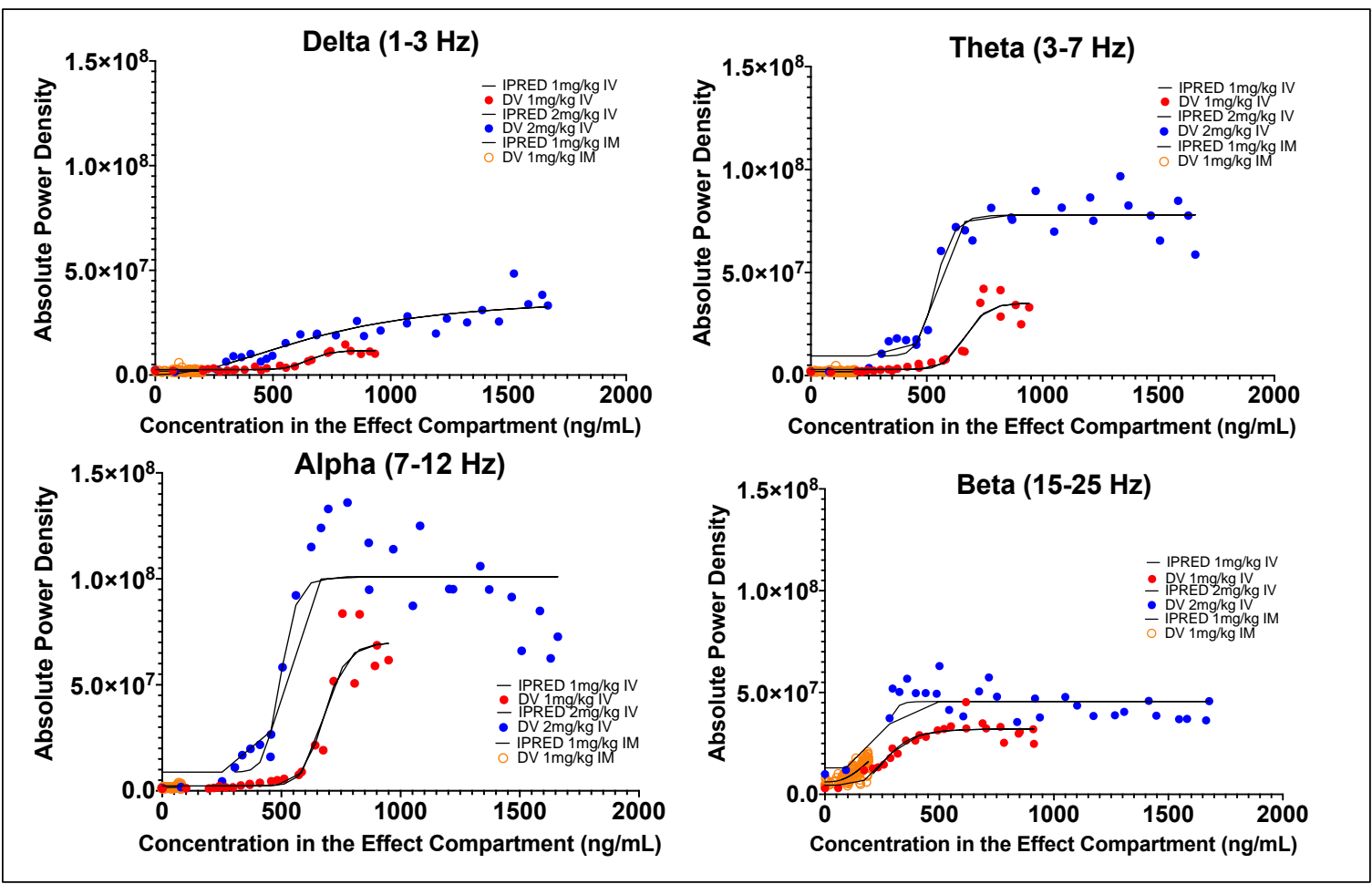


Figure 4b. iEEG Relative Power Density Effect-Concentration Profiles

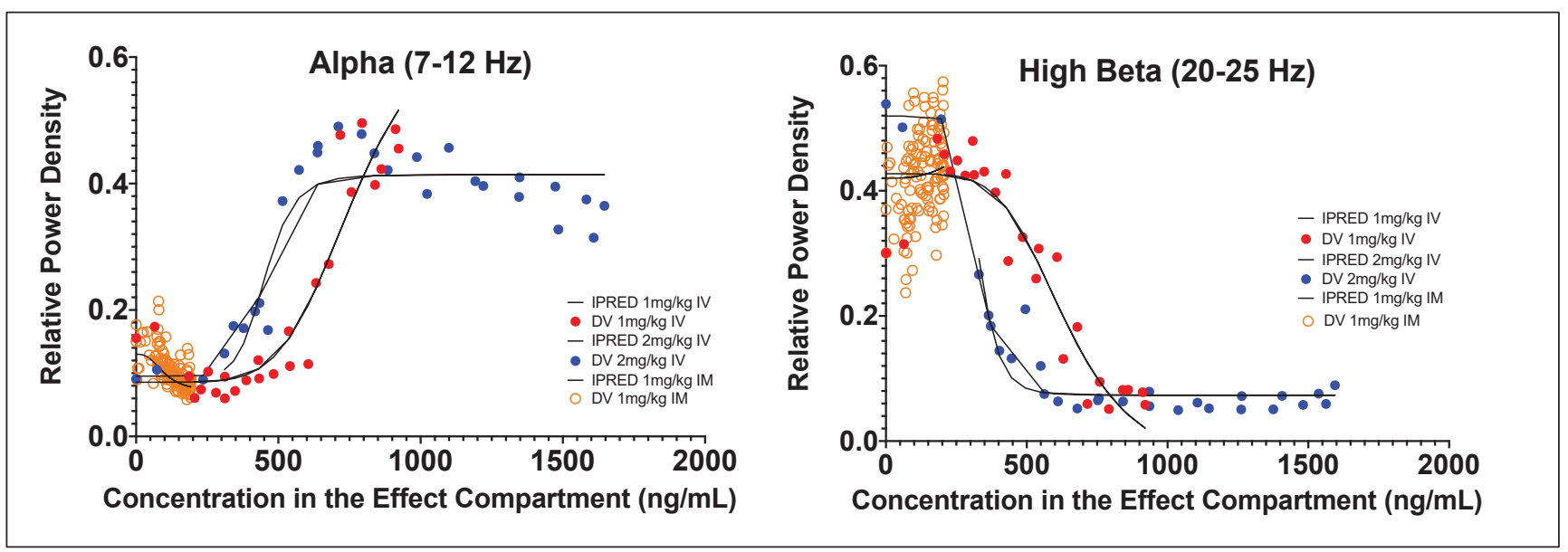


Figure 5. Plasma ALLO Concentration-Time Profiles Following IM Administration

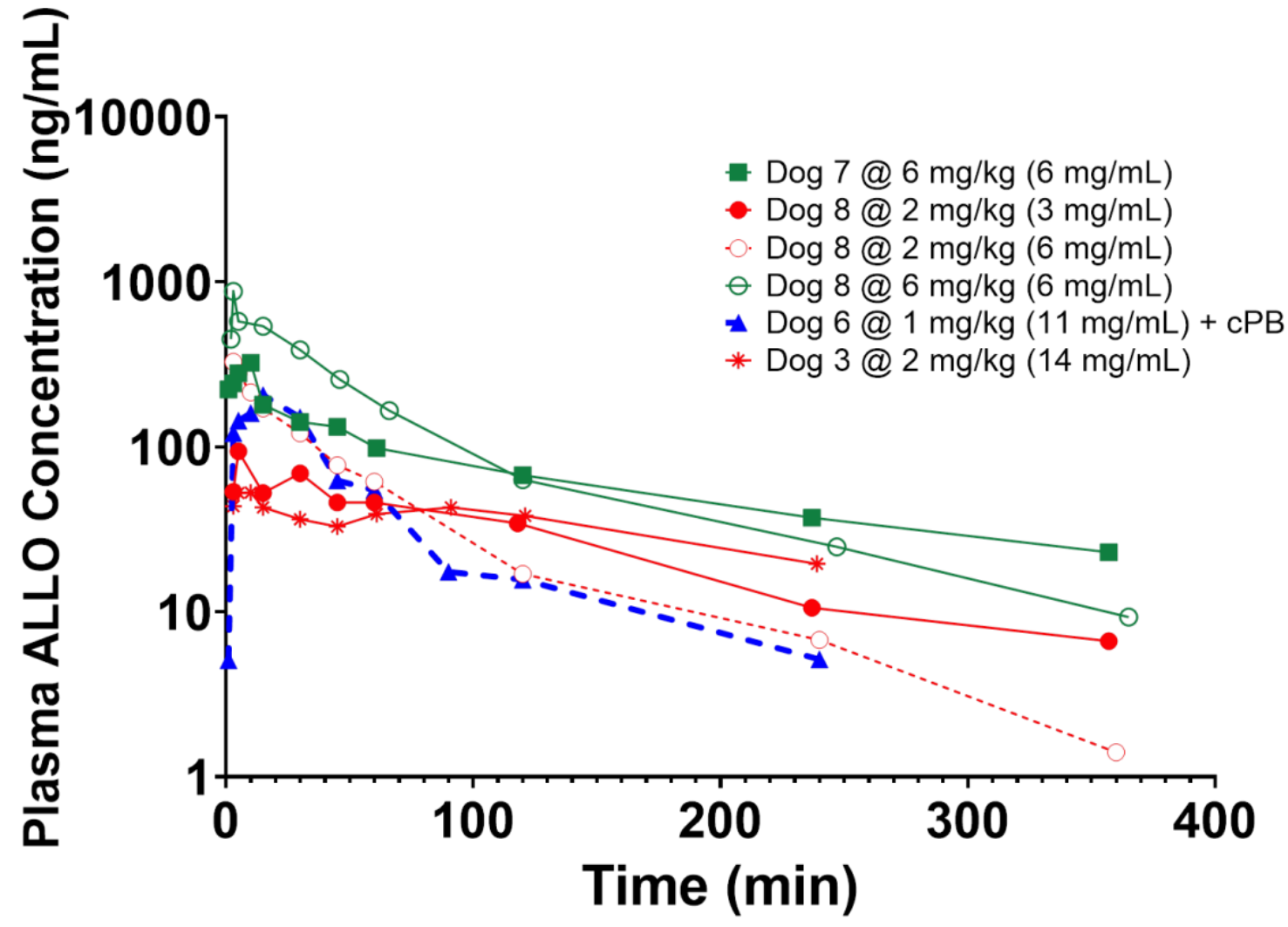


Figure 6. Bioavailability and Absorption of Different IM Injection Formulations

A)

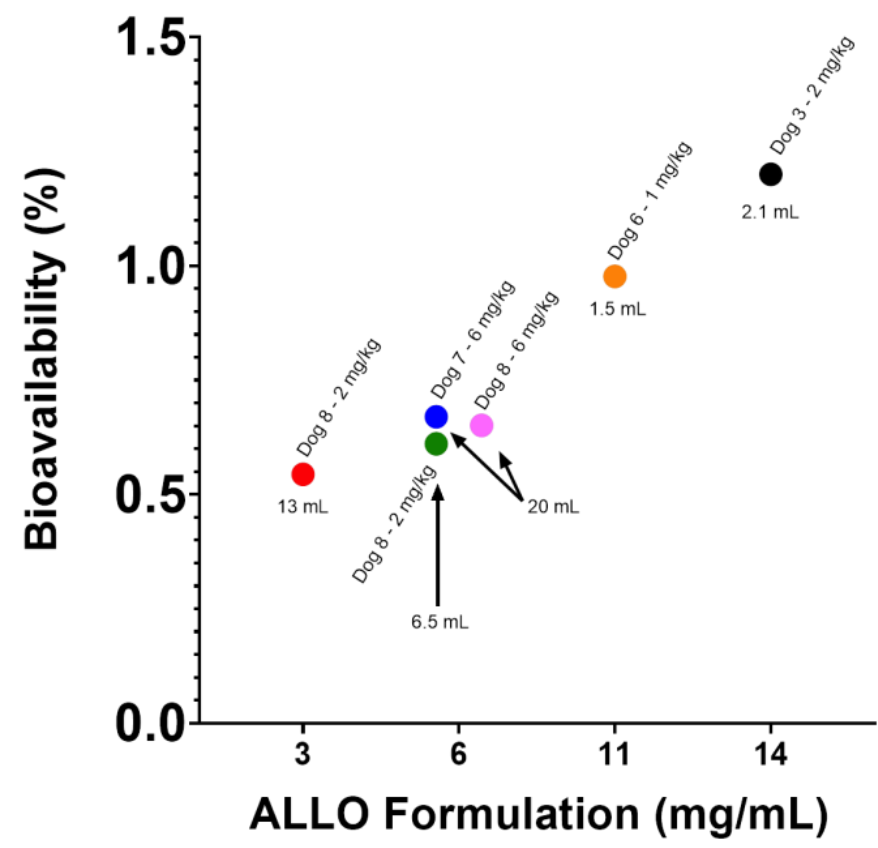

B)

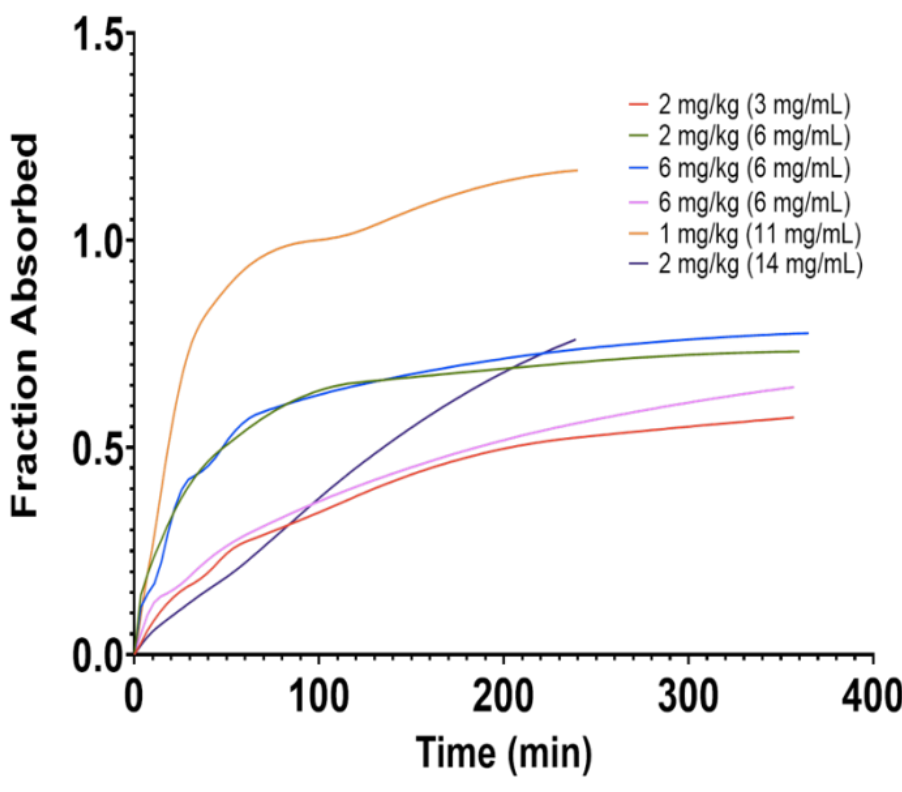


